\title{
The antitumor effects of geraniol: Modulation of cancer hallmark pathways (Review)
}

\author{
MINSOO CHO $^{1}$, INSUK SO ${ }^{2,3}$, JUNG NYEO CHUN ${ }^{2,3}$ and JU-HONG JEON ${ }^{2,3}$ \\ ${ }^{1}$ Undergraduate Research Program, ${ }^{2}$ Department of Physiology and Biomedical Sciences, \\ Seoul National University College of Medicine, Seoul 03080; ${ }^{3}$ Institute of Human-Environment \\ Interface Biology, Seoul National University, Seoul 03080, Republic of Korea
}

Received December 21, 2015; Accepted February 18, 2016

DOI: 10.3892/ijo.2016.3427

\begin{abstract}
Geraniol is a dietary monoterpene alcohol that is found in the essential oils of aromatic plants. To date, experimental evidence supports the therapeutic or preventive effects of geraniol on different types of cancer, such as breast, lung, colon, prostate, pancreatic, and hepatic cancer, and has revealed the mechanistic basis for its pharmacological actions. In addition, geraniol sensitizes tumor cells to commonly used chemotherapy agents. Geraniol controls a variety of signaling molecules and pathways that represent tumor hallmarks; these actions of geraniol constrain the ability of tumor cells to acquire adaptive resistance against anticancer drugs. In the present review, we emphasize that geraniol is a promising compound or chemical moiety for the development of a safe and effective multi-targeted anticancer agent. We summarize the current knowledge of the effects of geraniol on target molecules and pathways in cancer cells. Our review provides novel insight into the challenges and perspectives with regard to geraniol research and to its application in future clinical investigation.
\end{abstract}

\section{Contents}

1. Introduction

2. The effects of geraniol on cancer hallmarks

3. The effects of geraniol on various types of cancer

4. Discussion and future perspective

Correspondence to: Professor Ju-Hong Jeon or Jung Nyeo Chun, Department of Physiology and Biomedical Sciences, Seoul National University College of Medicine, 103 Daehak-ro, Jongno-gu, Seoul 03080, Republic of Korea

E-mail: jhjeon2@snu.ac.kr

E-mail: jnchun@gmail.com

Key words: geraniol, cancer, cancer hallmark, antitumor effect, molecular mechanism

\section{Introduction}

Monoterpenes, specifically the $\mathrm{C}_{10}$ isoprenoids, are dietary compounds that are found in the essential oils of many fruits, vegetables and herbs. Monoterpenes have been considered to play a physiological role in the mediation of plant-environment interactions (1). Monoterpenes have been widely used as flavorings and fragrances in the food and cosmetic industries, and as active ingredients in many pharmaceutical products due to their analgesic, anti-inflammatory, anti-pain and wound healing properties (2-9). Several dietary monoterpenes, such as $d$-limonene and perillyl alcohol, have been known to exert chemotherapeutic or chemopreventive effects against cancer (4,10-15).

Geraniol is an acyclic monoterpene alcohol that is derived from the essential oils of aromatic plants (see ref. 16 for the detailed physicochemical and toxicological properties of geraniol). In addition to its use in various commercial products, including cosmetics and fine fragrances, geraniol exerts a broad spectrum of pharmacological activities, such as anti-microbial, anti-inflammatory, anti-oxidant, anti-ulcer and neuroprotective activities (17-20). Geraniol has garnered attention for its potential role in the treatment of a range of cancers, including breast, lung, colon, prostate, pancreatic and hepatic cancers (21-26). In addition, geraniol has been shown to sensitize tumor cells to commonly used chemotherapy agents, such as 5-fluorouracil (5-FU) and docetaxel $(25,27,28)$. Because geraniol is classified into the generallyrecognized-as-safe (GRAS) category by the Flavor and Extract Manufacturers Association (FEMA) and the Food and Drug Administration (FDA) of the United States (16), its therapeutic effects against cancer have important clinical and translational implications.

Geraniol has been demonstrated to control multiple signaling molecules and pathways that are involved in various biological processes, such as the cell cycle, cell survival and proliferation, apoptosis, autophagy and metabolism $(22,23,25,29-31)$. Multi-target therapeutic agents are more efficacious for the treatment of complex diseases, such as cancer, and are less vulnerable to adaptive resistance (32-36). Therefore, geraniol may be a promising resource that may be used as an active ingredient, a lead compound, or a chemical moiety for future drug development. In the present review, we 


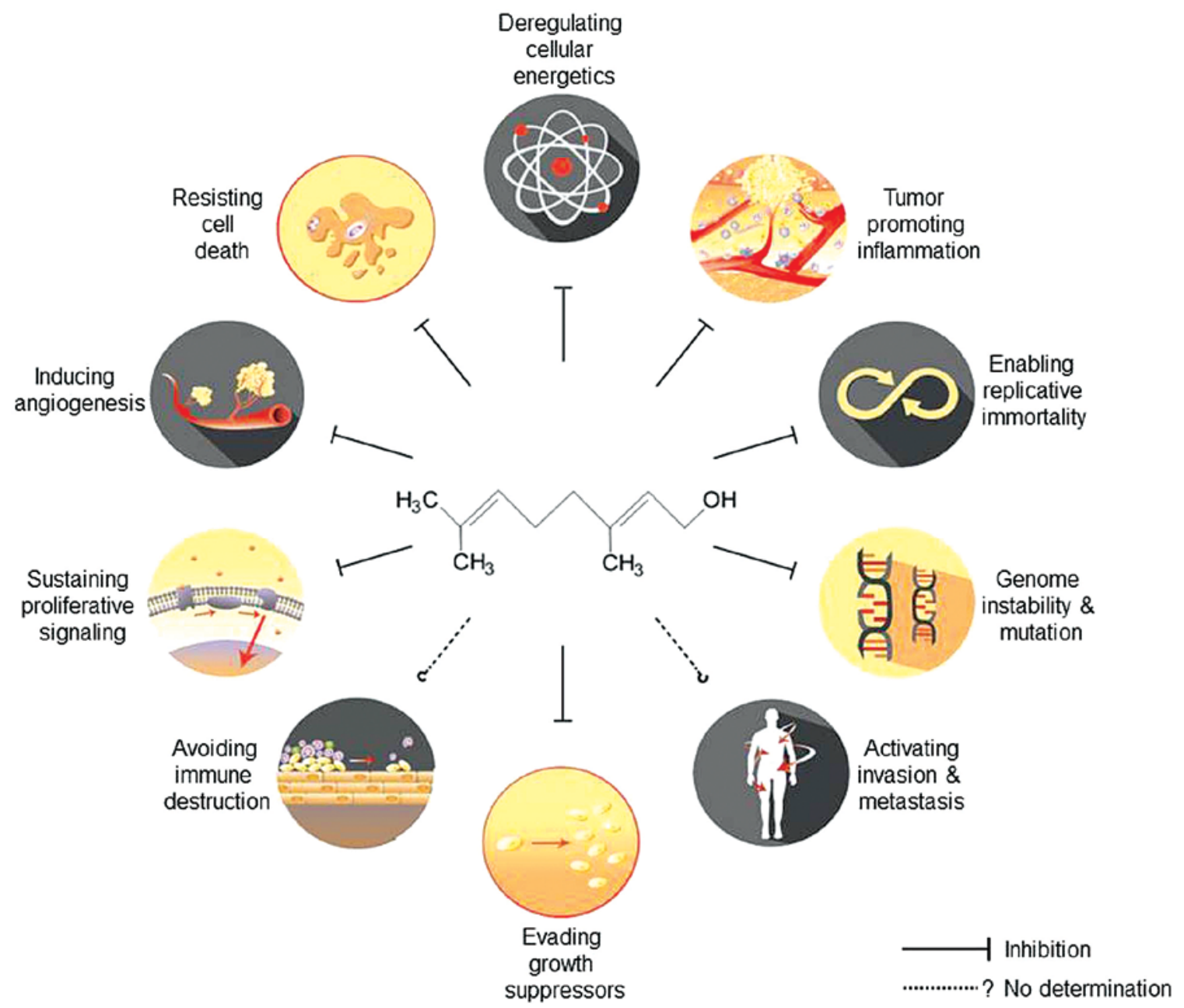

Figure 1. The multiple effects of geraniol on cancer hallmarks.

highlight the antitumor activity of geraniol against various types of cancer. We also summarize the current knowledge with regards to the effects of geraniol on target molecules or pathways. Our review provides novel insight into the challenges and perspectives of geraniol research as it pertains to future clinical investigations.

\section{The effects of geraniol on cancer hallmarks}

Successive genetic lesions promote the transition of a cell from a normal to a neoplastic state because they confer relative fitness benefits, which ensure a high degree of adaptability to altered environmental cues. When tumor cells evolve progressively under selective pressures, they acquire certain cancer hallmarks that enable the tumor to survive and grow and ultimately become malignant (37-42). Therefore, the molecules or pathways that are responsible for the acquisition of these hallmarks have been considered promising targets for the development of effective anticancer agents.

Geraniol has been demonstrated to affect many signaling molecules and pathways that represent cancer hallmarks, such as sustaining proliferative signaling (26,43-47), evading growth suppressors (30), enabling replicative immortality $(22,23,25,28,46,48-50)$, tumor-promoting inflammation (6-8,45,46,50-53), inducing angiogenesis $(46,54)$, genome instability and mutation (49), and resisting cell death $(25,26,30,45,46,49,50,54)$ and deregulating cellular energetics $(23,24,26,29-31,47,52)$. The pleiotropic effects of geraniol on cancer hallmarks are schematically illustrated in Fig. 1 and are summarized in Table I. However, the detailed molecular mechanisms through which geraniol functions will be described in the next section. These results suggest that geraniol effectively abolishes various properties of tumor cells that allow them to adapt and survive under selective pressure.

\section{The effects of geraniol on various types of cancer}

Geraniol has been found to be effective against a broad range of cancers, including breast, lung, colon, prostate, pancreatic, skin, liver, kidney and oral cancers (Fig. 2). The molecular mechanisms that underlie the therapeutic effects of geraniol on various types of cancer are summarized in Table II. Of cancer hallmarks, enabling replicative immortality and resisting cell death appear to be the most central targets of geraniol (Table II). However, it is emphasized that this can be research or publication bias: for example, it is still not reported whether geraniol affects avoidance of immune destruction or activating invasion and metastasis. The effective dose range of geraniol in vitro (cell culture), and in in vivo (xenograft or chemical carcinogenesis) models are presented in Table III. 
Table I. The effects of geraniol on cancer hallmarks.

Cancer hallmark

The affected molecule or pathway (ref.)

Sustaining proliferative signaling

c-fos $\downarrow$ (46), cholesterol $\downarrow$ (26,44), ERK1/2 $\downarrow$ (43,45), PKC $\downarrow$ (43), Ras $\downarrow$ (26,45), Raf $\downarrow$ (45), RhoA $\downarrow$ (47)

Evading growth suppressors

Avoiding immune destruction

Enabling replicative immortality

$\operatorname{pAKT} \downarrow, \operatorname{pmTOR} \downarrow(30)$

N.D. ${ }^{a}$

PCNA $\downarrow$ (46,50), cyclin-A $\downarrow(23,25,48)$, cyclin-B $\downarrow(25,48)$, cyclin-D1 $\downarrow(25,46,48)$, cyclin-E $\downarrow(23,25), \mathrm{CDK} 1 \downarrow, \mathrm{p} 27^{\mathrm{Kip} 1} \uparrow(25,48), \mathrm{CDK} 2 \downarrow(48), \mathrm{CDK} 4 \downarrow(23,25)$, $\mathrm{p} 21^{\mathrm{Cip} 1} \uparrow(25,48), \mathrm{ODC} \downarrow(22), \mathrm{TS} \downarrow, \mathrm{TK} \downarrow(28)$

Tumor-promoting inflammation

CAT $\uparrow(51,52), \mathrm{COX}-2 \downarrow(45,46,52), \mathrm{GPX} \uparrow(45,50,52)$, reduced-GSH $\uparrow(45,50,52)$, $\operatorname{GST} \uparrow(45,50), \mathrm{GR} \uparrow, \mathrm{MDA} \downarrow(45,52), \mathrm{NF}-\mathrm{kB} \downarrow(50,52), \mathrm{SOD} \uparrow(51,52)$, vitamin $\mathrm{E} \uparrow(51)$, $\mathrm{IL}-1 \beta \downarrow, \mathrm{IL}-6 \downarrow, \mathrm{TNF}-\alpha \downarrow, \mathrm{NO} \downarrow, \mathrm{pp} 38 \downarrow, \mathrm{QR} \uparrow(52), \mathrm{n}-\mathrm{Nrf}-2 \uparrow(53)$

Activating invasion and metastasis Inducing angiogenesis

Genome instability and mutation Resisting cell death

N.D.

VEGF $\downarrow$ (46), VEGFR-2 $\downarrow$ (54)

DNA damage $\downarrow$ (49)

ATG5 $\uparrow, \mathrm{LC} 3 \uparrow(30), \operatorname{Bax} \uparrow(25,45,46), \mathrm{Bcl}-2 \downarrow(25,30,45,46,49), \mathrm{Bax} \uparrow, \mathrm{Bcl}-\mathrm{xL} \downarrow$ (30), Bcl-w $\downarrow$, BNIP3 $\uparrow(25)$, caspase- $3 \uparrow(25,26,30,46,50,54)$, caspase- $8 \uparrow$ (50), caspase- $9 \uparrow$ $(46,50), \mathrm{Kim}-1 \downarrow(50), \mathrm{p} 53 \downarrow(46,50)$

Deregulating cellular energetics

G6PD $\uparrow \quad$ (52), HMG-CoA reductase $\downarrow(23,26,29,31,47)$, pAMPK $\uparrow$

${ }^{a}$ N.D., not determined. Arrows indicate upregulation or downregulation of the indicated molecules in terms of expression or activity. AMPK, AMP-activated protein kinase; ATG5, autophagy-related protein 5; Bax, Bcl2-associated X protein; Bcl-xL, B-cell lymphoma-extra large; Bcl-w, Bcl-2-like 2; Bcl-2, B-cell lymphoma 2; BNIP3, Bcl2/adenovirus E1B $19 \mathrm{kDa}$ interacting protein 3; CAT, catalase; CDK, cyclin-dependent kinase; COX-2, cyclooxygenase-2; ERK, extracellular signal-regulated kinase; GPX, glutathione peroxidase; GR, glutathione reductase; GSK-3 $\beta$, glycogen synthase kinase-3 $\beta$; GSH, glutathione; G6PD, glucose-6-phosphate dehydrogenase; HMG-CoA, 3-hydroxy-3-methylglutaryl-CoA; IL, interleukin; iNOS, inducible nitric oxide synthase; Kim-1, kidney injury molecule-1; LC3, microtubule-associated protein light chain 3; MDA, malondialdehyde; MPO, myeloperoxidase; mTOR, mammalian target of rapamycin; NF- $\mathrm{BB}$, nuclear factor-kappa B; NO, nitric oxide; n-Nrf-2, nuclear Nrf-2; ODC, ornithine decarboxylase; PCNA, proliferating cell nuclear antigen; PGE2, prostaglandin E2; pI $\kappa B-\alpha$, phospho-I kappa B-alpha; PKC, protein kinas C; PPAR $\gamma$, peroxisome proliferator-activated receptor gamma; RhoA, Ras homolog gene family member A; QR, quinone reductase; SOD, superoxide dismutase; TBARS, thiobarbituric acid reactive substances; TNF- $\alpha$, tumor necrosis factor- $\alpha$; TS, thymidylate synthase; TK, thymidine kinase, VEGF, vascular endothelia growth factor.

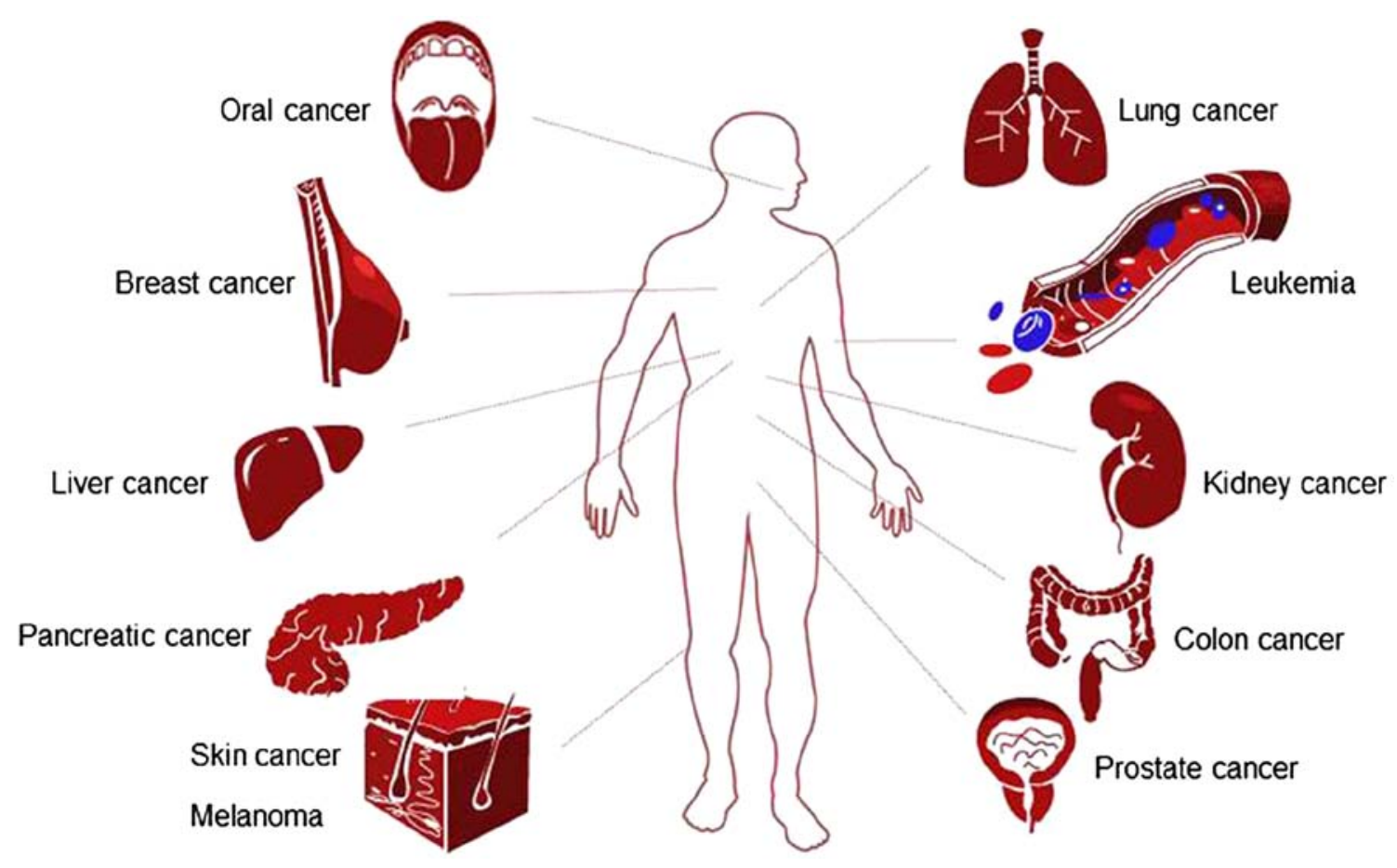

Figure 2. The cancer types that are sensitive to geraniol. 


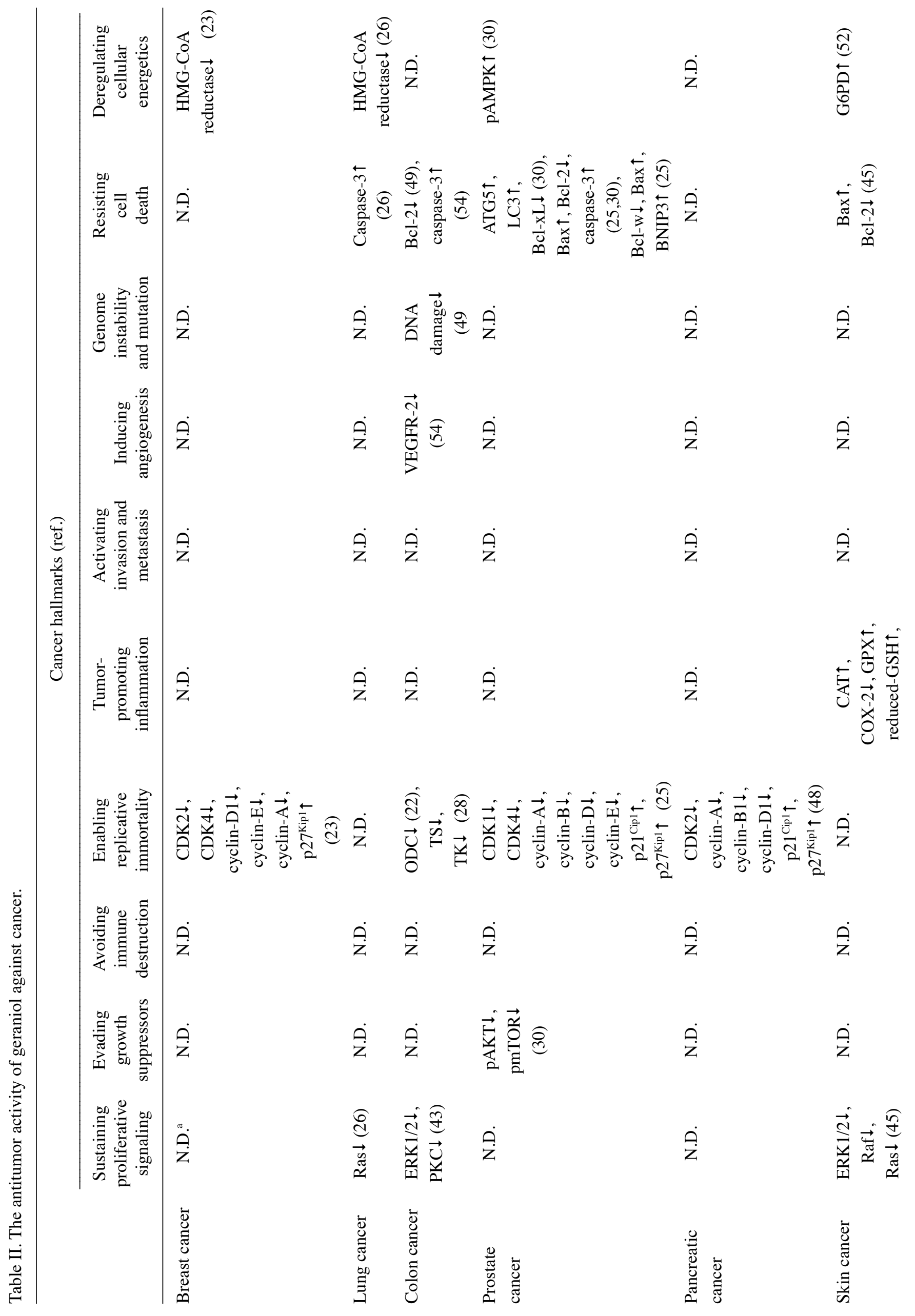




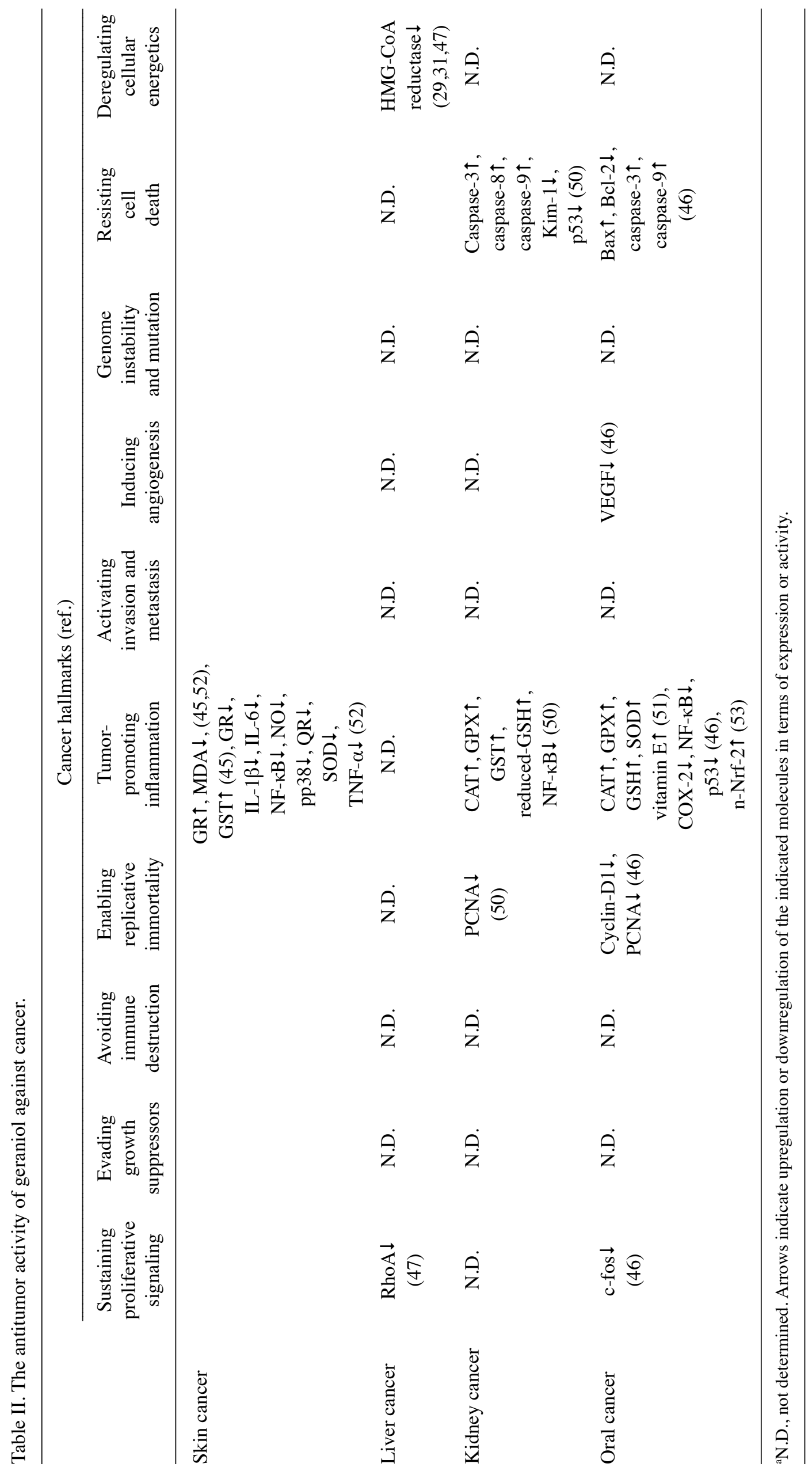


Table III. The effective doses of geraniol in cancer models.

\begin{tabular}{|c|c|c|c|}
\hline Cancer & Model & In vivo route & Effective dose (ref.) \\
\hline Breast & MCF-7 cell culture & & 300,500 and $700 \mu \mathrm{M}(23)$ \\
\hline Lung & $\begin{array}{l}\text { A549 cell culture } \\
\text { A549 xenograft }\end{array}$ & Oral & $\begin{array}{c}727.2 \mu \mathrm{M} \mathrm{(26)} \\
25,50 \text { and } 75 \mathrm{mmol} / \mathrm{kg}(26)\end{array}$ \\
\hline Colon & $\begin{array}{l}\text { Caco- } 2 \text { cell culture } \\
\text { SW620 cell culture } \\
\text { TC118 xenograft } \\
\text { Dimethylhydrazine-treated Wistar rat }\end{array}$ & $\begin{array}{l}\text { I.P. }^{\mathrm{a}} \\
\text { I.P. }\end{array}$ & $\begin{array}{c}150 \text { and } 400 \mu \mathrm{M}(22,27,28,43) \\
150 \mu \mathrm{M}(28) \\
150 \mathrm{mg} / \mathrm{kg}(28) \\
250 \mathrm{mg} / \mathrm{kg}(49)\end{array}$ \\
\hline Prostate & $\begin{array}{l}\text { PC-3 cell culture } \\
\text { PC-3 xenograft }\end{array}$ & I.T. ${ }^{\mathrm{a}}$ & $\begin{array}{l}250,500 \text { and } 1,000 \mu \mathrm{M}(25,30) \\
60 \mathrm{mg} / \mathrm{kg}(25)\end{array}$ \\
\hline Pancreatic & $\begin{array}{l}\text { MIA PaCa- } 2 \text { cell culture } \\
\text { BxPC- } 3 \text { cell culture } \\
\text { PC- } 1 \text { xenograft }\end{array}$ & Oral & $\begin{array}{c}100,200,400 \text { and } 500 \mu \mathrm{M}(21,48) \\
10,20,40,80,160,400 \text { and } 800 \mu \mathrm{M}(48,60) \\
20 \mathrm{~g} / \mathrm{kg}(21)\end{array}$ \\
\hline Skin & $\begin{array}{l}\text { 12-O-tetradecanoylphorbol } \\
\text { 13-acetate-treated mice }\end{array}$ & Dermal & 10,50 and $100 \mathrm{mg} / \mathrm{kg}(45,52)$ \\
\hline Liver & $\begin{array}{l}\text { HepG2 cell culture } \\
\text { Morris hepatoma } 7777 \text { xenograft } \\
\text { 2-acetylaminofluorene-treated Wistar rat }\end{array}$ & $\begin{array}{l}\text { Oral } \\
\text { Oral }\end{array}$ & $\begin{array}{c}100,200 \text { and } 400 \mu \mathrm{M}(29,31,61) \\
23 \mathrm{mmol} / \mathrm{kg}(62) \\
250 \mathrm{mg} / \mathrm{kg}(24,47)\end{array}$ \\
\hline Kidney & Ferric nitrilotriacetate-treated Wistar rat & Oral & 100 and $200 \mathrm{mg} / \mathrm{kg}(50)$ \\
\hline Oral & $\begin{array}{l}\text { 7,12-dimethylbenz }[\alpha] \text { anthracene-treated hamster } \\
\text { 4-niroquinoline-1-oxide-treated mice }\end{array}$ & $\begin{array}{l}\text { Oral } \\
\text { Oral }\end{array}$ & $\begin{array}{l}250 \text { and } 500 \mathrm{mg} / \mathrm{kg}(46,51) \\
200 \mathrm{mg} / \mathrm{kg}(53)\end{array}$ \\
\hline Other cancers & $\begin{array}{l}\text { B16 melanoma cell culture } \\
\text { B16 xenograft } \\
\text { P388 leukemia cell culture }\end{array}$ & Oral & $\begin{array}{c}150 \text { and } 160 \mu \mathrm{M}(64,66) \\
6.5 \text { and } 65 \mathrm{mmol} / \mathrm{kg}(62) \\
900 \mu \mathrm{M}(63)\end{array}$ \\
\hline
\end{tabular}

${ }^{a}$ I.P., intraperitoneal injection; I.T., intratumoral injection.

Breast cancer. Geraniol suppressed the growth of MCF-7 breast cancer cells via the induction of cell cycle arrest in the G1 phase (23). The protein levels of cyclin D1, cyclin-dependent kinase 4 (CDK4), cyclin E, and cyclin A were reduced in geraniol-treated MCF-7 cells, whereas those of $\mathrm{p} 27^{\mathrm{Kip} 1}$ were elevated by geraniol (23). In contrast, geraniol did not affect the growth of MCF-10F normal breast epithelial cells (23), which indicates that its activity is tumor-specific. Although geraniol inhibited 3-hydroxy-3-methylglutaryl coenzyme A (HMG$\mathrm{CoA}$ ) reductase activity, geraniol-induced cell cycle arrest was not rescued by supplementation with mevalonate, which is a reaction product of HMG-CoA reductase (23). These results indicate that the anti-proliferative effect of geraniol on MCF-7 cells is not related to a reduction in HMG-CoA reductase activity or the limitation of cellular mevalonate levels, but rather, that it is linked to other molecular mechanisms.

Lung cancer. Experiments in xenograft models revealed that geraniol reduced tumor weight and volume in mice bearing tumors that formed from A549 cells (26), which showed an increased TUNEL-positive tumor cell population and elevated caspase-3 activity. Geraniol also inhibited cholesterol synthesis in A549 cells and reduced the serum levels of cholesterol in mice with A549 cell xenografts through the suppression of HMG-CoA reductase activity (26). In addition, geraniol reduced the expression levels of membrane-bound Ras in A549 cell-bearing mice without corresponding changes in the total protein levels of Ras (26). This was probably due to the actions of geraniol that are related to the inhibition of mevalonate pathways and the resultant reduction in Ras prenylation (55). However, it is unclear whether mevalonate supplementation can rescue geraniol-induced phenotypes.

Colon cancer. Geraniol exerted anti-proliferative activity against Caco-2 colorectal adenocarcinoma cells through the induction of $\mathrm{S}$ phase cell cycle arrest (22). In addition, geraniol elicited apoptosis in mouse xenograft models using CT26 colon carcinoma cells (54). Geraniol affected polyamine metabolism in Caco-2 cells through the reduction of ornithine decarboxylase (ODC) activity (22). This is clinically relevant because polyamine metabolism is a promising target of chemotherapeutic and chemopreventive drug development strategies (56). Geraniol also induced the depolarization of the plasma membrane potential with a decrease in membrane resistance in Caco-2 cells (43), which led to the reduction in the activities of protein kinase $\mathrm{C}$ (PKC) and extracellular signal-regulated protein kinases (ERK) (43). Under the experimental conditions, mevalonate supplementation did 
not reverse geraniol-mediated inhibition of cell growth (43), which indicates that HMG-CoA reductase is not linked to the antitumor actions of geraniol.

Geraniol sensitized cultured Caco-2 cells and SW620 colorectal adenocarcinoma cells to 5-FU and also sensitized mice with xenografts of TC118 colon cancer cells to 5-FU $(27,28)$. In addition, geraniol elevated the uptake rate of 5-FU in colon cancer cells (27). Geraniol effectively decreased the expression levels of thymidine kinase and thymidylate synthase (28), which are important targets for the development of anticancer drugs and chemosensitizing agents (57-59). These results suggest that geraniol might serve as a chemosensitizer.

Geraniol was found to elicit chemopreventive activities (49). It decreased the total number of aberrant crypt foci in the colons of Wistar rats that were treated with dimethylhydrazine (49). Under this condition, geraniol reduced DNA damage in the colonic mucosa. In addition, apoptosis in the distal colon was significantly higher in the geraniol-treated group compared with the control group. Moreover, the expression levels of Bcl-2 were significantly decreased in the geranioltreated group (49).

Prostate cancer. Geraniol inhibited tumor cell growth via the induction of apoptosis in cultured and grafted PC-3 prostate cancer cells $(25,30)$ due to the depolarization of mitochondrial membrane potential, the activation of caspase-3, the reduction in the expression levels of Bcl-2 and Bcl-w, and the increased expression levels of Bax and BNIP3 (25). Geraniol also potently induced autophagy, which is crucial for the effective stimulation of cell death (30). The combined inhibition of apoptosis and autophagy restored cell growth in geraniol-treated PC-3 cells. In addition, cell cycle arrest at G1 phase, and a slight arrest at G2 phase, were observed in geraniol-treated PC-3 cells $(25,30)$, which was confirmed by the decreased expression levels of cyclins A, B, D and E and CDK1 and CDK4, as well as by the elevated levels of $\mathrm{p} 21^{\mathrm{Cip} 1}$ and $\mathrm{p} 27^{\mathrm{Kip} 1}$.

At the molecular level, geraniol has been found to inhibit AKT-mTOR signaling without affecting mitogen-activated protein kinase (MAPK) activity (30). For example, the PP2A inhibitor okadaic acid, but not the PP1 inhibitor tautomycin, reversed geraniol-mediated inhibition of AKT. Concomitantly, geraniol activated AMP-activated protein kinase (AMPK). The combined treatment with the AKT inhibitor perifosine and the AMPK activator AICAR synergistically inhibited tumor cell growth (30). However, under the condition, geraniol did not affect the activity of transient receptor potential melastatin type 8 (TRPM8) channel or calcium mobilization $(25,30)$. In addition, mevalonate supplementation did not reverse the geraniol-mediated inhibition of cell growth (30).

Geraniol increased the therapeutic response of PC-3 cells to chemotherapy agents, such as docetaxel, doxorubicin, paclitaxel, etoposide, 5-FU and cisplatin (25). Particularly, the combination of the sub-optimal doses of geraniol and docetaxel noticeably suppressed the growth of prostate cancer cells in culture and those in mouse xenografts; the percentage of active caspase-3-positive cells was markedly increased in tumor tissues that were treated with geraniol and docetaxel compared with the treatment of cells with either drug alone.
Pancreatic cancer. Geraniol inhibited the proliferation of MIA PaCa-2 pancreatic carcinoma cells and $\mathrm{BxPC}-3$ pancreatic adenocarcinoma cells and reduced tumor volume in hamsters injected with PC-1 pancreatic ductal adenocarcinoma cells $(21,48,60)$. In addition, geraniol induced $\mathrm{G} 1$ phase cell cycle arrest in MIA PaCa-2 cells (48) and elevated the expression levels of $\mathrm{p} 21^{\mathrm{Cip} 1}$ and $\mathrm{p} 27^{\mathrm{Kip} 1}$ but reduced those of cyclin A, cyclin B1 and CDK2. siRNAs against p21 $1^{\mathrm{Cip} 1}$ and p2 $7^{\mathrm{Kip} 1}$ subsequently alleviated geraniol-induced cell cycle arrest (48). Finally, the protein levels of cyclin D1 were reduced by geraniol in MIA PaCa-2 cells, but not in BxPC-3 cells (48).

When the tumor cells were incubated with geraniol before they were treated with gemcitabine, which is one of the firstline treatments for advanced pancreatic cancer, proliferation of BxPC-3 cells was significantly inhibited compared with when the cells were treated with either drug alone (60). In addition, geraniol markedly enhanced the apoptosis-inducing effect of gemcitabine on BxPC-3 cells (60).

Skin cancer. Geraniol inhibited skin edema and epidermal hyperplasia in mice that were stimulated with 12-O-tetradecanolyphorbal-13-acetate (TPA)/7, 12-dimethylbenzanthracene (DMBA) $(45,52)$. The chemopreventive effects of geraniol on skin tumorigenesis are ascribed to the activation of apoptotic pathways and the attenuation of Ras-mediated cell proliferation pathways. Particularly, geraniol reduced the levels of membrane-bound Ras in DMBA/TPA-stimulated mice (45) and also decreased Raf expression and ERK activity. However, it is unclear whether geraniol inhibits HMG-CoA reductase activity in this setting and whether mevalonate rescues the geraniol-induced phenotypic changes. In addition, geraniol suppressed the TPA-induced increase in cutaneous ODC activity and the thymidine incorporation rate in mouse skin (45).

Geraniol suppressed skin inflammation through the inhibition of cyclooxygenase (COX)-2 induction in DMBA/ TPA-treated mice (45). Geraniol also inhibited the altered expression of nuclear factor $(\mathrm{NF})-\kappa \mathrm{B}$; the production of cutaneous proinflammatory cytokines, such as tumor necrosis factor (TNF)- $\alpha$, interleukin (IL)-6, IL-1 $\beta$ and pp38; and the formation of superoxide dismutase (SOD) and nitric oxide (NO) (52). In addition, geraniol exerted antioxidant activity to reduce TPA-induced malondialdehyde (MDA) production through modulation of the following: glutathione (GSH), glutathione reductase (GR), glutathione peroxidase (GPX), glutathione-S-transferase (GST), catalase (CAT), lipid peroxidation, glucose 6-phosphate dehydrogenase (G6PD) and quinone reductase $(\mathrm{QR})(45,52)$.

Liver cancer. In one study, geraniol exerted anti-proliferative activity in HepG2 hepatocarcinoma cells $(29,31,61)$, and G1 phase cell cycle arrest and apoptosis were observed in geraniol-treated cells (31). In addition, geraniol suppressed tumor growth in mice that received transplanted Morris 7777 hepatoma cells (62). Geraniol inhibited HMG-CoA reductase activity in HepG2 cells and 2-acetylaminofluorene-treated Wistar rat $(29,47)$ and reduced the level of RhoA in hepatic membranes (47). Although geraniol affected various lipid metabolic pathways, including $\mathrm{HMG}-\mathrm{CoA}$ reductase or 
$\Delta 5$-desaturase $(29,31)$, it is uncertain whether its effects are linked to tumor suppression.

Geraniol exhibited chemopreventive activity against hepatocarcinogenesis in rats that were stimulated with diethylnitrosamine and 2-acetylaminofluorene. It also inhibited cell proliferation and DNA damage in preneoplastic lesions (PNLs) and caused an elevation in apoptosis in PNLs $(24,47)$.

Kidney cancer. Geraniol demonstrated chemopreventive activity in Wistar rats treated with ferric nitrilotriacetate (Fe-NTA) (50) in that it effectively reduced renal oxidative stress and tumor incidence via the modulation of multiple molecular targets that are involved in proliferation, apoptosis, or inflammation. Geraniol restored the activities of GSH-dependent antioxidant enzymes, such as glutathione S-transferase, glutathione peroxidase, and catalase in Fe-NTA-injected rats, which suppressed Fe-NTA-induced renal toxicity (50). In the rats that were treated with Fe-NTA and $\mathrm{N}$-nitrosodiethylamine, geraniol downregulated kidney injury molecule-1 (Kim-1), NF- $\kappa \mathrm{B}$, proliferating cell nuclear antigen (PCNA), and p53 and upregulated caspase-3, -8 and $-9(50)$.

Oral squamous cell carcinoma. Geraniol prevented DMBAinduced buccal pouch carcinogenesis in the hamster $(46,51)$. Its anti-inflammatory, anti-angiogenic, anti-proliferative, and apoptosis-inducing properties contributed to the suppression of histological changes, such as keratosis, dysplasia and hyperplasia, in the buccal pouch of DMBA-treated hamsters. Geraniol also exerted its chemopreventive potential against 4-nitroquinoline-1-oxide (4NQO)-induced oral carcinogenesis in Wistar rats (53).

Geraniol reduced the plasma concentrations of lipid peroxidation by-products in DMBA-stimulated hamsters (51). Geraniol also restored the DMBA-induced disturbance in the status of antioxidants in terms of glutathione peroxidase, reduced glutathione, vitamin $\mathrm{E}$, superoxide dismutase, and catalase in the plasma and in the buccal mucosa (51). In addition, the chemopreventive potential of geraniol relies on modulatory effects on phase I (cytochrome P450 and cytochrome b5) and II (glutathione-S-transferase, glutathione reductase and DT-diaphorase) detoxification enzymes to excrete carcinogenic metabolites during DMBA-induced buccal pouch carcinogenesis in the hamster (51). Similar effects of geraniol were observed in 4NQO-stimulated models of oral squamous cell carcinoma (53).

Geraniol reduced the expression levels of Bcl-2, PCNA, mutant p53, VEGF, c-fos, COX-2, NF- $\mathrm{B}$, and cyclin D1, whereas it elevated Bax, caspase- 3 and -9 activity in DMBAtreated hamsters (46). In addition, geraniol increased the nuclear levels of nuclear factor erythroid 2-related factor 2 (Nrf-2), a redox-sensitive transcription factor, in $4 \mathrm{NQO}-$ stimulated rats (53).

Other cancers. Geraniol inhibited cell growth in P388 leukemia cells (63). Geraniol exerted anti-proliferative activity against B16 melanoma cells in culture and in xenograft models (63-66). Mevalonate supplementation rescued geraniol-induced phenotypes of P388 leukemia cells, but not those of B16 melanoma cells (63). These results suggest that limitations in mevalonate levels suppress tumor growth in a cancer type-specific manner.

\section{Discussion and future perspective}

Geraniol has been approved as GRAS by FDA and FEMA. The acute oral $\mathrm{LD}_{50}$ was calculated as 3.6 to $4.8 \mathrm{~g} / \mathrm{kg}$ in rats and the intramuscular $\mathrm{LD}_{50}$ was reported to be $4 \mathrm{~g} / \mathrm{kg}$. In addition, dose toxicity was only slightly observed in repeated administration of geraniol at $1,000 \mathrm{mg} / \mathrm{kg} / \mathrm{day}$ in the diet for 16 weeks (see the ref. 16 for the detailed toxicological data of geraniol). The recent experimental observations obtained from in vitro and in vivo models have supported the idea that geraniol exerts therapeutic, chemosensitizing, or preventive effects against different cancer types by modulating multiple cancer hallmark pathways (Tables I and II). Particularly, the antitumor effects of geraniol were achieved by oral delivery in different cancer types (Table III), which is unlike poor oral bioavailability of many phytochemicals (67). These results suggest that geraniol might be beneficial for achieving a balance between therapeutic outcome and adverse drug responses and useful for improvement in quality of life of patients and palliative treatment. Therefore, geraniol might be promising for further development as a lead compound or a chemical moiety.

The non-toxic properties of geraniol (16) and the experimental results summarized in this review have demonstrated that geraniol specifically suppresses tumor growth, but does not affect normal physiology at an individual level. Geraniol commonly affects the signaling molecules that are involved in the acquisition of cancer hallmarks, particularly those that involve the cell cycle and apoptosis, across various types of cancer, as summarized in Tables I and II. These findings suggest that geraniol elicits tumor-specific effects through common molecular mechanisms. However, several geraniolreactive signaling pathways are also important physiological cell functions. For example, geraniol has been shown to inhibit angiogenesis, which does not only occur during tumor growth but also during embryo development, wound healing and other physiological conditions (68). Therefore, the cancer typespecific actions and the adverse effects of geraniol need to be carefully evaluated.

HMG-CoA reductase catalyzes the synthesis of mevalonate, which is the committed step in the synthesis of prenyl groups (55) and is the limiting step in cholesterol biosynthesis (69). The expression levels of HMG-CoA reductase are frequently upregulated in various types of cancer in humans $(23,26,29,31,47)$. It has been shown that geraniol inhibits HMG-CoA reductase in most types of tumor cells, which raises the possibility that the reduced prenylation of small G-proteins, such as Ras or RhoA, accounts for the antitumor effects of geraniol. However, mevalonate supplementation did not reverse geraniol-induced growth suppression in any type of cancer tested $(23,26)$ except leukemia $(63)$. These results suggest that geraniol-induced molecular changes do not necessarily induce phenotypic outcomes and that the inhibition of HMG-CoA reductase might be effective against specific types of cancer, including leukemia.

The molecular mechanisms by which geraniol exerts its anticancer effects are still largely unknown. Therefore, much effort is required to obtain additional information 
on the effectiveness and efficacy of geraniol. In this regard, computational approaches using omics technology-driven data should be emphasized to broaden our understanding of the pharmacological mechanisms of action of geraniol and for the translation of this biological knowledge into clinical practice (70-76). Data-driven approaches allow us novel insights into geraniol-induced changes in terms of the molecular makeup of biological systems, which contributes to the efficient discovery of the latent target molecules of geraniol.

There seem to be no doubt that geraniol inhibits cancer growth in vitro and in vivo models. However, in vitro models, submillimolar concentrations of geraniol have been used to define the therapeutic effects and the mechanism of action (Table III). This may be a weakness of geraniol studies because these concentrations are not clinically relevant. Nonetheless, geraniol effectively and efficiently suppresses tumor growth in in vivo models. These findings are similar to those of metformin, an anti-diabetic drug. Although millimolar concentrations of metformin usually exerts anticancer activity in in vitro models, there is consensus that metformin is a clinically promising cancer therapeutic agent $(77,78)$. Therefore, it is crucial that the mechanisms of action of geraniol are elucidated in in vivo studies.

The present review has highlighted the pleiotropic mechanisms of action of geraniol in various types of cancer. Geraniol is therefore useful in the development of multi-target therapies against cancer, and our review provides a scientific basis for future basic and translational research.

\section{Acknowledgements}

We are very grateful to Ms. Da-Kyung Lee, Ms. Young Hyun Yun, and Prof. Jeong Han Kim (Bio-Medical Arts and Design Education Center, Department of Contemporary Art and Ceramics and Fiber Arts, College of Fine Art, Seoul Women's University) for preparation of the figures. This research was supported by the National Research Foundation of Korea (NRF) funded by the Ministry of Science, ICT and Future Planning (2014R1A2A1A11050616) and the Education and Research Encouragement Fund of Seoul National University Hospital.

\section{References}

1. Mahmoud SS and Croteau RB: Strategies for transgenic manipulation of monoterpene biosynthesis in plants. Trends Plant Sci 7: 366-373, 2002

2. Guimarães AG, Quintans JS and Quintans LJ Jr: Monoterpenes with analgesic activity: a systematic review. Phytother Res 27: $1-15,2013$.

3. de Cássia da Silveira e Sá R, Andrade LN and de Sousa DP: A review on anti-inflammatory activity of monoterpenes. Molecules 18: 1227-1254, 2013

4. Bhalla Y, Gupta VK and Jaitak V: Anticancer activity of essential oils: A review. J Sci Food Agric 93: 3643-3653, 2013.

5. Barreto RS, Albuquerque-Júnior RL, Araújo AA, Almeida JR, Santos MR, Barreto AS, DeSantana JM, Siqueira-Lima PS, Quintans JS and Quintans-Júnior LJ: A systematic review of the wound-healing effects of monoterpenes and iridoid derivatives. Molecules 19: 846-862, 2014.

6. Hasan SK and Sultana S: Geraniol attenuates 2-acetylaminofluorene induced oxidative stress, inflammation and apoptosis in the liver of wistar rats. Toxicol Mech Methods 25: 559-573, 2015.
7. Medicherla K, Sahu BD, Kuncha M, Kumar JM, Sudhakar G and Sistla R: Oral administration of geraniol ameliorates acute experimental murine colitis by inhibiting pro-inflammatory cytokines and NF- $\kappa B$ signaling. Food Funct 6: 2984-2995, 2015.

8. Soubh AA, Abdallah DM and El-Abhar HS: Geraniol ameliorates TNBS-induced colitis: Involvement of $\mathrm{Wnt} / \beta$-catenin, p38MAPK, NF- $\kappa B$, and PPAR $\gamma$ signaling pathways. Life Sci 136: $142-150,2015$.

9. Kozioł A, Stryjewska A, Librowski T, Sałat K, Gaweł M, Moniczewski A and Lochyński S: An overview of the pharmacological properties and potential applications of natural monoterpenes. Mini Rev Med Chem 14: 1156-1168, 2014.

10. Gould MN: Cancer chemoprevention and therapy by monoterpenes. Environ Health Perspect 105 (Suppl 4): 977-979, 1997.

11. Crowell PL: Prevention and therapy of cancer by dietary monoterpenes. J Nutr 129: 775S-778S, 1999.

12. Chen TC, Fonseca CO and Schönthal AH: Preclinical development and clinical use of perillyl alcohol for chemoprevention and cancer therapy. Am J Cancer Res 5: 1580-1593, 2015.

13. Samaila D, Toy BJ, Wang RC and Elegbede JA: Monoterpenes enhanced the sensitivity of head and neck cancer cells to radiation treatment in vitro. Anticancer Res 24: 3089-3095, 2004.

14. Bardon S, Foussard V, Fournel S and Loubat A: Monoterpenes inhibit proliferation of human colon cancer cells by modulating cell cycle-related protein expression. Cancer Lett 181: 187-194, 2002.

15. Sobral MV, Xavier AL, Lima TC and de Sousa DP: Antitumor activity of monoterpenes found in essential oils. Sci World J 2014: 953451, 2014.

16. Lapczynski A, Bhatia SP, Foxenberg RJ, Letizia CS and Api AM: Fragrance material review on geraniol. Food Chem Toxicol 46 (Suppl 11): S160-S170, 2008.

17. Solórzano-Santos F and Miranda-Novales MG: Essential oils from aromatic herbs as antimicrobial agents. Curr Opin Biotechnol 23: 136-141, 2012.

18. Tiwari $\mathrm{M}$ and Kakkar P: Plant derived antioxidants - Geraniol and camphene protect rat alveolar macrophages against t-BHP induced oxidative stress. Toxicol In Vitro 23: 295-301, 2009.

19. de Carvalho KI, Bonamin F, Dos Santos RC, Périco LL, Beserra FP, de Sousa DP, Filho JM, da Rocha LR and HirumaLima CA: Geraniol - a flavoring agent with multifunctional effects in protecting the gastric and duodenal mucosa. Naunyn Schmiedebergs Arch Pharmacol 387: 355-365, 2014.

20. Rekha KR, Selvakumar GP, Sethupathy S, Santha K and Sivakamasundari RI: Geraniol ameliorates the motor behavior and neurotrophic factors inadequacy in MPTP-induced mice model of Parkinson's disease. J Mol Neurosci 51: 851-862, 2013.

21. Burke YD, Stark MJ, Roach SL, Sen SE and Crowell PL: Inhibition of pancreatic cancer growth by the dietary isoprenoids farnesol and geraniol. Lipids 32: 151-156, 1997.

22. Carnesecchi S, Schneider Y, Ceraline J, Duranton B, Gosse F, Seiler N and Raul F: Geraniol, a component of plant essential oils, inhibits growth and polyamine biosynthesis in human colon cancer cells. J Pharmacol Exp Ther 298: 197-200, 2001.

23. Duncan RE, Lau D, El-Sohemy A and Archer MC: Geraniol and beta-ionone inhibit proliferation, cell cycle progression, and cyclin-dependent kinase 2 activity in MCF-7 breast cancer cells independent of effects on HMG-CoA reductase activity. Biochem Pharmacol 68: 1739-1747, 2004.

24. Ong TP, Heidor R, de Conti A, Dagli ML and Moreno FS: Farnesol and geraniol chemopreventive activities during the initial phases of hepatocarcinogenesis involve similar actions on cell proliferation and DNA damage, but distinct actions on apoptosis, plasma cholesterol and HMGCoA reductase. Carcinogenesis 27: 1194-1203, 2006.

25. Kim SH, Bae HC, Park EJ, Lee CR, Kim BJ, Lee S, Park HH, Kim SJ, So I, Kim TW, et al: Geraniol inhibits prostate cancer growth by targeting cell cycle and apoptosis pathways. Biochem Biophys Res Commun 407: 129-134, 2011.

26. Galle M, Crespo R, Kladniew BR, Villegas SM, Polo M and de Bravo MG: Suppression by geraniol of the growth of A549 human lung adenocarcinoma cells and inhibition of the mevalonate pathway in culture and in vivo: Potential use in cancer chemotherapy. Nutr Cancer 66: 888-895, 2014.

27. Carnesecchi S, Langley K, Exinger F, Gosse F and Raul F: Geraniol, a component of plant essential oils, sensitizes human colonic cancer cells to 5-Fluorouracil treatment. J Pharmacol Exp Ther 301: 625-630, 2002. 
28. Carnesecchi S, Bras-Gonçalves R, Bradaia A,Zeisel M, Gossé F, Poupon MF and Raul F: Geraniol, a component of plant essential oils, modulates DNA synthesis and potentiates 5-fluorouracil efficacy on human colon tumor xenografts. Cancer Lett 215 53-59, 2004

29. Polo MP and de Bravo MG: Effect of geraniol on fatty-acid and mevalonate metabolism in the human hepatoma cell line Hep G2. Biochem Cell Biol 84: 102-111, 2006.

30. Kim SH, Park EJ, Lee CR, Chun JN, Cho NH, Kim IG, Lee S, Kim TW, Park HH, So I, et al: Geraniol induces cooperative interaction of apoptosis and autophagy to elicit cell death in PC-3 prostate cancer cells. Int J Oncol 40: 1683-1690, 2012.

31. Crespo R, Montero Villegas S, Abba MC, de Bravo MG and Polo MP: Transcriptional and posttranscriptional inhibition of HMGCR and PC biosynthesis by geraniol in 2 Hep-G2 cell proliferation linked pathways. Biochem Cell Biol 91: 131-139, 2013.

32. Zimmermann GR, Lehár J and Keith CT: Multi-target therapeutics: When the whole is greater than the sum of the parts. Drug Discov Today 12: 34-42, 2007

33. Efferth $\mathrm{T}$ and Koch E: Complex interactions between phytochemicals. The multi-target therapeutic concept of phytotherapy. Curr Drug Targets 12: 122-132, 2011.

34. Rather MA, Bhat BA and Qurishi MA: Multicomponent phytotherapeutic approach gaining momentum: Is the 'one drug to fit all' model breaking down? Phytomedicine 21: 1-14, 2013.

35. Tao L, Zhu F, Xu F, Chen Z, Jiang YY and Chen YZ: Co-targeting cancer drug escape pathways confers clinical advantage for multi-target anticancer drugs. Pharmacol Res 102: $123-131,2015$.

36. Huang S and Kauffman S: How to escape the cancer attractor: Rationale and limitations of multi-target drugs. Semin Cancer Biol 23: 270-278, 2013.

37. Hanahan D and Weinberg RA: The hallmarks of cancer. Cell 100: 57-70, 2000.

38. Hanahan D and Weinberg RA: Hallmarks of cancer: The next generation. Cell 144: 646-674, 2011

39. Floor SL, Dumont JE, Maenhaut C and Raspe E: Hallmarks of cancer: Of all cancer cells, all the time? Trends Mol Med 18 509-515, 2012.

40. Ellenbroek SI and van Rheenen J: Imaging hallmarks of cancer in living mice. Nat Rev Cancer 14: 406-418, 2014.

41. Horne SD, Pollick SA and Heng HH: Evolutionary mechanism unifies the hallmarks of cancer. Int J Cancer 136: 2012-2021, 2015.

42. Sonnenschein $C$ and Soto AM: The aging of the 2000 and 2011 Hallmarks of Cancer reviews: A critique. J Biosci 38: 651-663, 2013.

43. Carnesecchi S, Bradaia A, Fischer B, Coelho D, SchöllerGuinard M, Gosse F and Raul F: Perturbation by geraniol of cell membrane permeability and signal transduction pathways in human colon cancer cells. J Pharmacol Exp Ther 303: 711-715, 2002.

44. Hoshi D, Nakajima A, Inoue E, Shidara K, Sato E, Kitahama M, Seto Y, Tanaka E, Urano W, Ichikawa N, et al: Incidence of serious respiratory infections in patients with rheumatoid arthritis treated with tocilizumab. Mod Rheumatol 22: 122-127, 2012.

45. Chaudhary SC, Siddiqui MS, Athar M and Alam MS: Geraniol inhibits murine skin tumorigenesis by modulating COX-2 expression, Ras-ERK1/2 signaling pathway and apoptosis. J Appl Toxicol 33: 828-837, 2013.

46. Vinothkumar V, Manoharan S, Sindhu G, Nirmal MR and Vetrichelvi V: Geraniol modulates cell proliferation, apoptosis, inflammation, and angiogenesis during 7,12-dimethylbenz[a] anthracene-induced hamster buccal pouch carcinogenesis. Mol Cell Biochem 369: 17-25, 2012.

47. Cardozo MT, de Conti A, Ong TP, Scolastici C, Purgatto E, Horst MA, Bassoli BK and Moreno FS: Chemopreventive effects of $\beta$-ionone and geraniol during rat hepatocarcinogenesis promotion: Distinct actions on cell proliferation, apoptosis HMGCoA reductase, and RhoA. J Nutr Biochem 22: 130-135, 2011.

48. Wiseman DA, Werner SR and Crowell PL: Cell cycle arrest by the isoprenoids perillyl alcohol, geraniol, and farnesol is mediated by $\mathrm{p} 21^{\mathrm{Cipl}}$ and $\mathrm{p} 27^{\mathrm{Kipl}}$ in human pancreatic adenocarcinoma cells. J Pharmacol Exp Ther 320: 1163-1170, 2007.
49. Vieira A, Heidor R, Cardozo MT, Scolastici C, Purgatto E, Shiga TM, Barbisan LF, Ong TP and Moreno FS: Efficacy of geraniol but not of $\beta$-ionone or their combination for the chemoprevention of rat colon carcinogenesis. Braz J Med Biol Res 44: 538-545, 2011.

50. Ahmad ST, Arjumand W, Seth A, Nafees S, Rashid S, Ali N and Sultana S: Preclinical renal cancer chemopreventive efficacy of geraniol by modulation of multiple molecular pathways. Toxicology 290: 69-81, 2011.

51. Vinothkumar V and Manoharan S: Chemopreventive efficacy of geraniol against 7,12-dimethylbenz[a]anthracene-induced hamster buccal pouch carcinogenesis. Redox Rep 16: 91-100, 2011.

52. Khan AQ, Khan R, Qamar W, Lateef A, Rehman MU, Tahir M, Ali F, Hamiza OO, Hasan SK and Sultana S: Geraniol attenuates 12-O-tetradecanoylphorbol-13-acetate (TPA)-induced oxidative stress and inflammation in mouse skin: Possible role of p38 MAP Kinase and NF-кB. Exp Mol Pathol 94: 419-429, 2013.

53. Madankumar A, Jayakumar S, Gokuladhas K, Rajan B, Raghunandhakumar S, Asokkumar S and Devaki T: Geraniol modulates tongue and hepatic phase I and phase II conjugation activities and may contribute directly to the chemopreventive activity against experimental oral carcinogenesis. Eur J Pharmacol 705: 148-155, 2013.

54. Wittig C, Scheuer C, Parakenings J, Menger MD and Laschke MW: Geraniol suppresses angiogenesis by downregulating vascular endothelial growth factor (VEGF)/VEGFR-2 signaling. PLoS One 10: e0131946, 2015.

55. Gysin S, Salt M, Young A and McCormick F: Therapeutic strategies for targeting ras proteins. Genes Cancer 2: 359-372, 2011.

56. Wallace HM: Targeting polyamine metabolism: A viable therapeutic/preventative solution for cancer? Expert Opin Pharmacother 8: 2109-2116, 2007.

57. Peters GJ, Backus HH, Freemantle S, van Triest B, CodacciPisanelli G, van der Wilt CL, Smid K, Lunec J, Calvert AH, Marsh S, et al: Induction of thymidylate synthase as a 5-fluorouracil resistance mechanism. Biochim Biophys Acta 1587: 194-205, 2002

58. Popat S, Matakidou A and Houlston RS: Thymidylate synthase expression and prognosis in colorectal cancer: A systematic review and meta-analysis. J Clin Oncol 22: 529-536, 2004.

59. Topolcan $\mathrm{O}$ and Holubec $\mathrm{L}$ Jr: The role of thymidine kinase in cancer diseases. Expert Opin Med Diagn 2: 129-141, 2008.

60. Jin X, Sun J, Miao X, Liu G and Zhong D: Inhibitory effect of geraniol in combination with gemcitabine on proliferation of BXPC-3 human pancreatic cancer cells. J Int Med Res 41: 993-1001, 2013

61. Polo MP, Crespo R and de Bravo MG: Geraniol and simvastatin show a synergistic effect on a human hepatocarcinoma cell line. Cell Biochem Funct 29: 452-458, 2011.

62. Yu SG, Hildebrandt LA and Elson CE: Geraniol, an inhibitor of mevalonate biosynthesis, suppresses the growth of hepatomas and melanomas transplanted to rats and mice. J Nutr 125: 2763-2767, 1995

63. Shoff SM, Grummer M, Yatvin MB and Elson CE: Concentrationdependent increase of murine P388 and B16 population doubling time by the acyclic monoterpene geraniol. Cancer Res 51: 37-42, 1991.

64. He L, Mo H, Hadisusilo S, Qureshi AA and Elson CE: Isoprenoids suppress the growth of murine B16 melanomas in vitro and in vivo. J Nutr 127: 668-674, 1997.

65. Mo H, Tatman D, Jung M and Elson CE: Farnesyl anthranilate suppresses the growth, in vitro and in vivo, of murine B16 melanomas. Cancer Lett 157: 145-153, 2000.

66. McAnally JA, Jung M and Mo H: Farnesyl-O-acetylhydroquinone and geranyl-O-acetylhydroquinone suppress the proliferation of murine B16 melanoma cells, human prostate and colon adenocarcinoma cells, human lung carcinoma cells, and human leukemia cells. Cancer Lett 202: 181-192, 2003.

67. Aqil F, Munagala R, Jeyabalan J and Vadhanam MV: Bioavailability of phytochemicals and its enhancement by drug delivery systems. Cancer Lett 334: 133-141, 2013.

68. Chung AS and Ferrara N: Developmental and pathological angiogenesis. Annu Rev Cell Dev Biol 27: 563-584, 2011.

69. DeBose-Boyd RA: Feedback regulation of cholesterol synthesis: Sterol-accelerated ubiquitination and degradation of HMG CoA reductase. Cell Res 18: 609-621, 2008. 
70. Chun JN, Lim JM, Kang Y, Kim EH, Shin YC, Kim HG, Jang D, Kwon D, Shin SY, So I, et al: A network perspective on unraveling the role of TRP channels in biology and disease. Pflugers Arch 466: 173-182, 2014.

71. Barabási AL, Gulbahce N and Loscalzo J: Network medicine: A network-based approach to human disease. Nat Rev Genet 12: 56-68, 2011.

72. Furlong LI: Human diseases through the lens of network biology. Trends Genet 29: 150-159, 2013.

73. Ideker T and Krogan NJ: Differential network biology. Mol Syst Biol 8: 565, 2012.

74. Grossglauser M and Saner H: Data-driven healthcare: From patterns to actions. Eur J Prev Cardiol 21 (Suppl): 14-17, 2014.
75. Lusher SJ, McGuire R, van Schaik RC, Nicholson CD and de Vlieg J: Data-driven medicinal chemistry in the era of big data. Drug Discov Today 19: 859-868, 2014

76. Quan Y, Wang ZY, Xiong M, Xiao ZT and Zhang HY: Dissecting traditional Chinese medicines by omics and bioinformatics. Nat Prod Commun 9: 1391-1396, 2014.

77. Quinn BJ, Kitagawa H, Memmott RM, Gills JJ and Dennis PA: Repositioning metformin for cancer prevention and treatment. Trends Endocrinol Metab 24: 469-480, 2013.

78. Anisimov VN: Do metformin a real anticarcinogen? A critical reappraisal of experimental data. Ann Transl Med 2: 60, 2014. 